\title{
Influence of Citrus Rootstocks in Bioactive Compounds of Clementines
}

\author{
Pilar Legua ${ }^{1, *}$, Francisca Hernández ${ }^{1}$, María Ángeles Forner-Giner² \\ ${ }^{1}$ Miguel Hernández University, Department of Plant Sciences and Microbiology, Research Group in Plant Production and Technology, \\ Ctra. de Beniel, Orihuela, Alicante, Spain \\ ${ }^{2}$ Centro de Citricultura y Producción Vegetal. Instituto Valenciano de Investigaciones Agrarias (IVIA), Apartado Oficial, \\ Moncada, Valencia, Spain \\ *Corresponding author: p.legua@umh.es
}

\begin{abstract}
Citrus fruit is one of the most important commercial fruit crops in the world. It is essential to use citrus rootstocks in this crop, since all varieties, whether, oranges, tangerines, lemons and grapefruits are highly sensitive to Phytophthora spp., present in almost all soils. Selection of optimal rootstock is crucial for commercial cultivation of citrus fruit, as the effect fruit production, tree size, diseases, and adaptation to certain soil conditions. Besides, rootstock may affect internal quality parameters of citrus fruits, including juice total, soluble solids, acidity, antioxidant capacity, sugars and organic acids content, flavor. In this study, we evaluated the effect of three rootstocks (Carrizo citrange, C-35 citrange and Forner-Alcaide 5) on physicochemical parameters, sugars and organic acids, total antioxidant activity, total phenolic, crude fibre content and flavonoids, of 'Clemenrubí' and 'Orogrós' clementines. The results indicate that the effect of rootstock on the physicochemical parameters, antioxidant activity, total phenolic, sugars and organic acids and flavonoids of clementines fruits is a rather complex phenomenon that greatly depends on specific interactions between the rootstock and each particular scion variety. C-35 citrange rootstock produced the heaviest and bigger size fruits, while the rootstock Forner-Alcaide 5 produced the fruit with the major flavonoid content.
\end{abstract}

Keywords: clementines, organic acids, polyphenolic profile, rootstock, sugars

Cite This Article: Pilar Legua, Francisca Hernández, and María Ángeles Forner-Giner, "Influence of Citrus Rootstocks in Bioactive Compounds of Clementines." Journal of Food and Nutrition Research, vol. 5, no. 8 (2017): 545-552. doi: 10.12691/jfnr-5-8-3.

\section{Introduction}

Citrus fruit is one of the most important commercial fruit crops in the world. Spain produces 2.4 million tons of mandarins, being the second largest producer in the world, and being the largest exporter [1]. It is essential to use citrus rootstocks in this crop, since all varieties, whether; oranges, tangerines, lemons and grapefruits are highly sensitive to Phytophthora spp., present in almost all soils. Rootstocks have a large impact on scion growth habit and fruit yield and quality [2]. Besides, rootstock may affect internal quality parameters of citrus fruits, including juice total, soluble solids, titratable acidity, antioxidant capacity, sugars and organic acids content, flavor $[3,4,5]$.

Carrizo citrange [Citrus sinensis (L.) Osb. $\times$ Poncirus trifoliata (L.) Raf.] is currently the most important rootstock used in Spain, employed in over $80 \%$ of nursery production [6]. Recently some Spanish Orchards have been planted with C-35 citrange $(C$. sinensis $\times P$. trifoliata $)$ rootstock; it is resistant to the citrus nematode (Tylenchuslus semipenetrans Cob.) and trees on this rootstock also reach a smaller size than Carrizo citrange [7]. Forner-Alcaide 5 is a new citrus rootstock released from the citrus rootstock breeding program of Instituto Valenciano de Investigaciones Agrarias (IVIA), this rootstock is resistant to Citrus Tristeza Virus (CTV), tolerant to salinity [8], iron chlorosis [9], and citrus nematode [10]. In addition, it produces high yiled and excellent quality fruit [11].

Citrus fruits and derived products have a beneficial effect on human health because of their nutritional and antioxidant properties, and their consumption is associated with a decrease in the incidence of cardiovascular disease and reduced risk of certain cancers [12].

In the present study, we evaluated, for the first time, the effect of three rootstocks (Carrizo citrange, C-35 citrange and Forner-Alcaide 5 (FA-5)) on physicochemical parameters, sugars and organic acids, total antioxidant activity, total phenolic, crude fibre content and flavonoids, of 'Clemenrubí' and 'Orogrós' clementines. Both clementines are early mutations from 'Oronules' and are being registered in EU and commercialized in Spain. The information generated will help breeders to select the best rootstock for their plantations of clementines. 


\section{Materials and Methods}

\subsection{Plant Material and Experimental Design}

Seeds of Carrizo citrange and C-35 were obtained from the germplasm collection of rootstocks at IVIA and the seeds of the FA-5 from the plants obtained in the citrus rootstock breeding program.

All nursery processes were performed in an aphid-proof greenhouse, with cooling system temperature ranging between 18 and $27^{\circ} \mathrm{C}$ and relative humidity of about $80 \%$. The trees were grown in the nursery using standard practices and, were planted in Algemesi (Valencia, Spain).

The plot was planted in May, 2005 under screenhouse in order to avoid sun-burning. The experimental design was a randomized complete block, with twelve trees per plot.

The soil was sandy-loam, $(\mathrm{pH} 8.2,38.2 \%$ sand, $40.5 \%$ silt, $21.3 \%$ clay, $1.4 \%$ organic matter and $26.8 \% \mathrm{CaCO} 3$ ). The grove was cultivated, pruned and sprayed, according to local practices. The soil was kept free of weeds using post-emergence herbicides.

\subsection{Preparation of Juice Sample}

The clementines (Citrus clementina Hort. ex Tan.) cv. 'Clemenrubí' and 'Orogrós', fruits were harvested at optimum maturity and immediately transferred to the laboratory of the Department of Plant Science and Microbiology, University Miguel Hernández Elche, Spain. Research was carried out using $30 \mathrm{~kg}$ of clementines from each variety/rootstock combination. Forty-five homogeneous fruits (based on color, size, and absence of defects) were selected per scion/stock for physical and chemical determinations. Three subsamples (each one composed by 10 fruits) were made at random, and then the fruits from each subsample were cutting in half and careful handsqueezing in a commercial kitchen juicer. The freshly squeezed juices were centrifuged at $15,000 \mathrm{rpm}$ and $4^{\circ} \mathrm{C}$ for 20 min (Sigma 3-18K centrifuge, Sigma Laborzentrifugen $\mathrm{GmbH}$, Osterode and Harz, Germany) and were kept in freezer at temperature of $-18^{\circ} \mathrm{C}$ until analysis, while the remaining 15 fruits per scion/stock were freeze-dried for polyphenolic compounds determination.

\subsection{Physicochemical Analyses}

For each fruit, the following parameters were measured: maximum width or equatorial diameter, ED ( $\mathrm{mm})$, and fruit length, FL (mm), using a digital calliper (model CD-15 DC; Mitutoyo (UK) Ltd, Telford, UK) with 0.01 $\mathrm{mm}$ accuracy; fruit weight, FW (g) using a digital scale Sartorius (model BL-600, with an accuracy of $0.01 \mathrm{~g}$ ).

Total soluble solids (TSS) were determined according to [11] with a hand-held refractometer (Atago Co., model $\mathrm{N}-1$, Tokyo, Japan, $0.2^{\circ}$ Brix accuracy) and expressed as degrees Brix at $20^{\circ} \mathrm{C}$. Titratable acidity (TA) and $\mathrm{pH}$ were determined using an automatic titration device (877 Titrino plus, Metrohm ion analyses CH9101, Herisau, Switzerland) with $0.1 \mathrm{~N} \mathrm{NaOH}$ up to $\mathrm{pH} 8.1$ using $1 \mathrm{~mL}$ of diluted juice in $25 \mathrm{~mL}$ of distilled $\mathrm{H}_{2} \mathrm{O}$, and results were expressed as g citric acid equivalent per $100 / \mathrm{g}$ fw, since this is the dominant organic acid in orange. The ratio, also known as the ripening index (RI), was calculated as the relation between TSS and TA. All analysis was performed in triplicate.

Colour determinations were made for juice $(n=3)$. The CIELAB L* (brightness or lightness; $0=$ black, $100=$ white $), a^{*}\left(-a^{*}=\right.$ greenness, $+a^{*}=$ redness $)$ and $b^{*}\left(-b^{*}=\right.$ blueness, $+b^{*}=$ yellowness $)$ color variables were measured using a Chroma Meter (C-300 Minolta Corp., Osaka, Japan) coupled to a Minolta DP-301 data processor. These values were then used to calculate Hue angle degree $\left[\mathrm{H}^{\mathrm{o}}=\operatorname{arctang}\left(\mathrm{b}^{*} / \mathrm{a}^{*}\right)\right]$, where $0^{\circ}=$ red-purple; $90^{\circ}=$ yellow, $180^{\circ}=$ bluish-green and $270^{\circ}=$ blue and Chroma $\left[\mathrm{C}^{*}=\left(\mathrm{a}^{* 2}+\mathrm{b}^{* 2}\right)\right]^{1 / 2}$, indicative of the intensity or color saturation.

The crude fibre (CF) contents were determined by a digester, an Ankon fiber analyzer (model A220, Macedon, NY, USA), following the official methodology established by the Spanish Ministry of Agriculture, Fisheries and Food [13]. Results were expressed as g $100 \mathrm{~g}^{-1} \mathrm{dw}$ (dry weight). Three repetitions per variety/rootstock combination were carried out.

\subsection{Analysis of Sugars and Organic Acids Contents}

Individual organic acids and sugars were also determined using three juice samples for each scion/stock combination as described by [14]. Briefly, one milliliter of the extract was filtered through a $0.45 \mu \mathrm{m}$ Millipore filter and then injected into a HPLC (Hewlett-Packard, series 1100, Wilmington Del., USA). The elution system consisted of $0.1 \%$ phosphoric acid with a flow rate of $0.5 \mathrm{~mL} \mathrm{~min}{ }^{-1}$. The organic acids were eluted through a Supelco column [SupelcogelTM C-610H column $(30 \mathrm{~cm} \times 7.8 \mathrm{~mm})$ ] and a Supelguard column $(5 \mathrm{~cm} \times 4.6 \mathrm{~mm}$, Supelco, Inc., Bellefonte, PA, USA) and detected by absorbance at 210 nm. For sugar determinations, the same HPLC, elution system, flow rate and columns were used. Sugars were detected with a refractive index detector (Hewlett-Packard, series 1100, G1362A, Wilmington Del., USA). A standard curve of pure organic acids (oxalic, citric, tartaric, malic, acetic, fumaric, succinic and L-ascorbic acids) and a standard curve of pure sugars (glucose, maltose, fructose, sucrose and sorbitol) purchased from Sigma (Poole, Dorset, UK) were used for quantification. Calibration curves, obtained by triplicate injection of standard solutions, were used for quantification purposes and showed good linearity (R2>0.999). Results for both individual organic acids and sugars were expressed as $\mathrm{g} 100 \mathrm{~mL}^{-1}$. Three repetitions per variety/rootstock combination were carried out.

\subsection{Total antioxidant activity (TAA)}

TAA was quantified by spectrophotometry as described by [15]. This procedure allowed determining both the hydrophilic and lipophilic TAA in the same extraction. Briefly, for each subsample, $5 \mathrm{~mL}$ of citrus juice were homogenized in $5 \mathrm{~mL}$ of $50 \mathrm{mM}$ phosphate buffer $\mathrm{pH}=7.8$ and $3 \mathrm{~mL}$ of ethyl acetate, then centrifuged at $10000 \times \mathrm{g}$ for $15 \mathrm{~min}$ at $4{ }^{\circ} \mathrm{C}$. The upper fraction was used for TAA due to lipophilic compounds (L-TAA) and the lower for TAA due to hydrophilic compounds (H-TAA). In both 
cases, TAA was determined in triplicate in each extract using the enzymatic system composed of the chromophore 2,2' -azino-bis-(3-ethylbenzothiazoline-6-sulfonic acid) diammonium salt (ABTS), the horse radish peroxidase enzyme and its oxidant substrate (hydrogen peroxide), in which ABTS $\bullet+$ radicals are generated and monitored at $730 \mathrm{~nm}$. The decrease in absorbance after adding the extract was proportional to TAA of the sample. A calibration curve was performed with Trolox ((R)-(+)-6-hydroxy2,5,7,8-tetramethyl-croman-2-carboxylic acid) (0 to $20 \mathrm{nmol}$ ) from Sigma (Madrid, Spain), and results are expressed as mg of Trolox equivalent (TE) $100 \mathrm{~g}^{-1} \mathrm{fw}$. Three repetitions per variety/rootstock combination were carried out.

\subsection{Total Phenolic Content by Folin-Ciocalteau's Reagent}

Total phenolic content (TPC) was quantified using Folin-Ciocalteu reagent as described by [16]. Absorption was measured for the sample at $760 \mathrm{~nm}$ using spectrophotometer (ThermoSpectronic Heyios $\gamma$, England). Three repetitions per variety/rootstock combination were carried out and results were expressed as mg of gallic acid equivalent (GAE) $100 \mathrm{~g}^{-1} \mathrm{fw}$.

\subsection{HPLC-DAD-ESI-MS ${ }^{\mathrm{n}}$ Analysis, Identification and Quantification of Phenolic Compounds}

$50 \mathrm{mg}$ of lyophilized sample was mixture with $1 \mathrm{~mL}$ of $\mathrm{MeOH}$ and then mixing was carried out by vortex, and the extraction was performed in an ultrasonic bath for $1 \mathrm{~min}$ at room temperature. The extract was centrifuge at 4, 000 rpm for 4 min and passed through a $0.45 \mu \mathrm{m}$ PTFE filter (Waters, Milford, USA) prior to injection into the chromatographic system.

Chromatographic analysis was performed on an Agilent 1100 series HPLC-ESI-DAD-MS ${ }^{\mathrm{n}}$ Ion Trap (Waldbronn, Germany). A reversed-phase Agilent Pursuit XRs 5 C18 column $(250 \times 4.6 \mathrm{~mm}$ i.d. and particle size $5 \mu \mathrm{m}$, Waldbronn, Germany). Water/formic acid (95:5, v/v) and acetonitrile were used as mobile phases $\mathrm{A}$ and $\mathrm{B}$, respectively, with a flow rate of $0.8 \mathrm{~mL} \mathrm{~min}^{-1}$. The gradient started with $5 \%$ of solvent $\mathrm{B}$, reaching $60 \%$ solvent $\mathrm{B}$ at $37 \mathrm{~min}$, and $98 \%$ at $40 \mathrm{~min}$, which was maintained up to $2 \mathrm{~min}$. The injection volume was $10 \mu \mathrm{L}$. Chromatographic comparison with analytical standards, absorbance spectra, and mass spectra, using $\mathrm{MS}^{\mathrm{n}}$ (data not shown) experiments, were used to identify compounds. Flavanones and C-glucoside were monitored and quantified at $360 \mathrm{~nm}$.

Three repetitions per variety/rootstock combination were carried out and results were expressed as $\mathrm{mM}$ of hesperiden for flavanones and as quercetin for $\mathrm{C}$-glucoside.

\subsection{Statistical Analyses}

All data were subjected to two-way analysis of variance, ANOVA [factors: (i) clementines cultivar and (ii) rootstocks]. Least significant difference (LSD) multi-comparison test was used to determine significant differences among treatments. Significance of differences was represented as $p \leq 0.05$. Statistical analyses were performed using SPSS 20.0 for Windows (SPSS Science, Chicago, IL, USA).

\section{Results and Discussion}

\subsection{Physicochemical Parameters}

The results of the physicochemical parameters are presented in Table 1. The factor "rootstock" significantly affected fruit weight and equatorial diameter. C-35 citrange produced the heaviest and bigger size fruits (Table 1). A study reported about 'Navelina' orange cultivar that C-35 citrange also induced the greatest weight and fruit size [11]. The interaction "rootstock $\times$ variety" was significantly for chemical parameters $(\mathrm{pH}$, TSS, TA and RI). In general, 'Clemenrubí' variety grafted on Carrizo citrange and FA-5 has higher content in TSS (Figure 1a). Regarding, the interaction "rootstock $\times$ variety" for TA 'Clemenrubí' grafted on the three rootstocks assayed showed higher values of TA compared with 'Orogrós' (Figure 1c), while with respect to $\mathrm{pH}$ was 'Orogrós' which showed higher values (Figure 1d). [17] reported about "Lane Late" navel orange on four citrus rootstocks that the rootstock affect on fruit juice acidity, and RI; also, [5] in a study about effects of rootstock/scion combinations on the flavor of citrus fruit found that TSS and acidity levels in juice fruits depend of rootstock/scion combination; however, other authors found that the effects of rootstock on fruit juice acidity and RI were non-significant $[18,19,20]$. The ripening index (TSS/TA) is an important parameter related to quality characteristics of citrus fruits [21] and it is also the best criterion in correlating fruit quality with consumer acceptance [22]. 'Orogrós' grafted on C-35 citrange showed the higher ripening index (Figure 1b). In general, RI value for acceptance of consumers since a pleasant taste is achieved when it is greater than 10 [23]. Besides, 'Orogrós' fruits reached higher values of juice TSS and lower TA fruits grafted on C-35 citrange and they could have improved the flavor of the juice and therefor the commercial quality and consumer acceptance. Data obtained in this study from citrus rootstock showed the influence of rootstock and variety in the physical and chemical fruit parameters. Besides, it clear that, the effect of rootstocks on some physical and chemical parameters of citrus fruits is a rather complex phenomenon that greatly depends on specific interactions between the rootstock and each particular scion variety.

Color is considered one of the most important external factors of fruit quality, as fruit appearance greatly influences consumers. In temperate countries, this non-destructive method can be applied in the field as well as in the industry to accurately show the apparent maturation degree of the fruit [24]. The factor "rootstock" significantly affected all color parameters; however, the interaction "rootstock $\times$ variety" only affected $a^{*}$ and $\mathrm{H}^{\circ *}$ parameters (Table 2). Fruits of trees grafted on Carrizo citrange was more luminous in color juice (higher $\mathrm{L}^{*}$ parameter). On the other hand, trees grafted onto Carrizo citrange and FA-5 produced fruit with the most intense orange colored juice (higher a* parameter) (Table 2). In Figure 2e, it shows that 'Clemenrubí' grafted on C-35 citrange presented the lowest values of $\mathrm{a}^{*}$, while 'Orogrós' showed the higher values. The fruits with best juice color were produced on FA-5. 
Table 1. Effect of citrus rootstocks on fruit weight, size, $\mathrm{pH}$, total soluble solids, titratable acidity and ripening index of clementines cv. 'Clemenrubí' and 'Orogrós'

\begin{tabular}{|c|c|c|c|c|c|c|c|}
\hline a'Parameters & FW (g) & ED (mm) & FL (mm) & pH & TSS & $\mathbf{T A}$ & RI \\
\hline \multicolumn{8}{|l|}{ Rootstock } \\
\hline Carrizo citrange & $83.8 b^{b}$ & $54.2 \mathrm{~b}$ & 51.1 & $4.9 \mathrm{a}$ & 10.9 & $9.8 \mathrm{~b}$ & $11.1 \mathrm{a}$ \\
\hline C-35 citrange & 103.9 a & $59.2 \mathrm{a}$ & 51.6 & $5.03 \mathrm{a}$ & 10.3 & $11.8 \mathrm{a}$ & $9.4 \mathrm{~b}$ \\
\hline FA-5 & $90.3 \mathrm{~b}$ & $55.7 \mathrm{~b}$ & 50.9 & $3.9 \mathrm{~b}$ & 10.8 & $11.5 \mathrm{a}$ & $9.3 \mathrm{~b}$ \\
\hline \multicolumn{8}{|l|}{ Variety } \\
\hline Clemenrubí & 90.6 & 90.6 & 51.2 & 3.5 & 10.7 & 12.2 & 9.1 \\
\hline Orogrós & 94.7 & 94.7 & 51.2 & 5.8 & 10.6 & 9.9 & 10.8 \\
\hline \multicolumn{8}{|l|}{ ANOVA $^{\mathrm{a}}$} \\
\hline Rootstock & $* * *$ & $* * *$ & NS & $* *$ & NS & $* *$ & $* * *$ \\
\hline Variety & NS & NS & NS & $* * *$ & NS & $* * *$ & $* * *$ \\
\hline Rootstock x Variety & NS & NS & NS & $* *$ & $* *$ & $* * *$ & $* * *$ \\
\hline
\end{tabular}

${ }^{\mathrm{a}} \mathrm{NS}=$ not significant at $\mathrm{p}<0.05 ; *, * *$, and ${ }^{* * *}$, significant at $\mathrm{p}<0.05,0.01$, and 0.001 , respectively.

${ }^{b}$ Values followed by the same letter, within the same column, were not significantly different $(\mathrm{p}<0.05)$, according to Least significant difference test (LSD). FW, fruit weight; ED, equatorial diameter; FL, fruit length; TA, titratable acidity (g citric acid $\left.\mathrm{L}^{-1}\right)$; TSS, total soluble solids ( $\left.{ }^{\circ} \mathrm{Brix}\right)$; RI, ripening index (TSS/TA)

Table 2. Effect of citrus rootstocks on juice colour of clementines cv. 'Clemenrubí' and 'Orogrós'

\begin{tabular}{|c|c|c|c|c|c|}
\hline${ }^{\mathrm{a}}$ Parameters & $\mathbf{L}^{*}$ & $a^{*}$ & $\mathbf{b}^{*}$ & $\mathrm{C}^{*}$ & $\mathbf{H}^{\mathbf{*}}$ \\
\hline \multicolumn{6}{|l|}{ Rootstock } \\
\hline Carrizo citrange & $40.5 \mathrm{a}^{\mathrm{b}}$ & $1.9 \mathrm{a}$ & $8.3 \mathrm{a}$ & $8.5 \mathrm{a}$ & $76.8 \mathrm{a}$ \\
\hline C-35 citrange & $39.5 \mathrm{~b}$ & $1.8 \mathrm{~b}$ & $7.7 \mathrm{~b}$ & $7.9 \mathrm{~b}$ & $76.8 \mathrm{a}$ \\
\hline FA-5 & $38.5 \mathrm{c}$ & $1.9 \mathrm{a}$ & $7.5 \mathrm{~b}$ & $7.7 \mathrm{~b}$ & $75.4 \mathrm{~b}$ \\
\hline \multicolumn{6}{|l|}{ Variety } \\
\hline Clemenrubí & 39.6 & 1.8 & 7.8 & 8.1 & 77.1 \\
\hline Orogrós & 39.4 & 1.9 & 7.8 & 8.1 & 75.7 \\
\hline \multicolumn{6}{|l|}{ ANOVA $^{\mathrm{a}}$} \\
\hline Rootstock & $* * *$ & $* *$ & $* * *$ & $* * *$ & $* * *$ \\
\hline Variety & NS & $* * *$ & NS & NS & $* * *$ \\
\hline Rootstock x Variety & NS & $* * *$ & NS & NS & $* * *$ \\
\hline
\end{tabular}

${ }^{a} \mathrm{NS}=$ not significant at $\mathrm{p}<0.05 ; * * *$, and $* * *$, significant at $\mathrm{p}<0.05,0.01$, and 0.001 , respectively.

${ }^{\mathrm{b}}$ Values followed by the same letter, within the same column, were not significantly different $(\mathrm{p}<0.05)$, according to Least significant difference test (LSD).

$\mathrm{L}^{*}=$ lightness; $\mathrm{a}^{*}=$ green/red coordinate; $\mathrm{b}^{*}=$ blue/yellow coordinate; $\mathrm{C}^{*}=$ chroma $; \mathrm{H}^{\mathrm{o}}=$ hue angle.
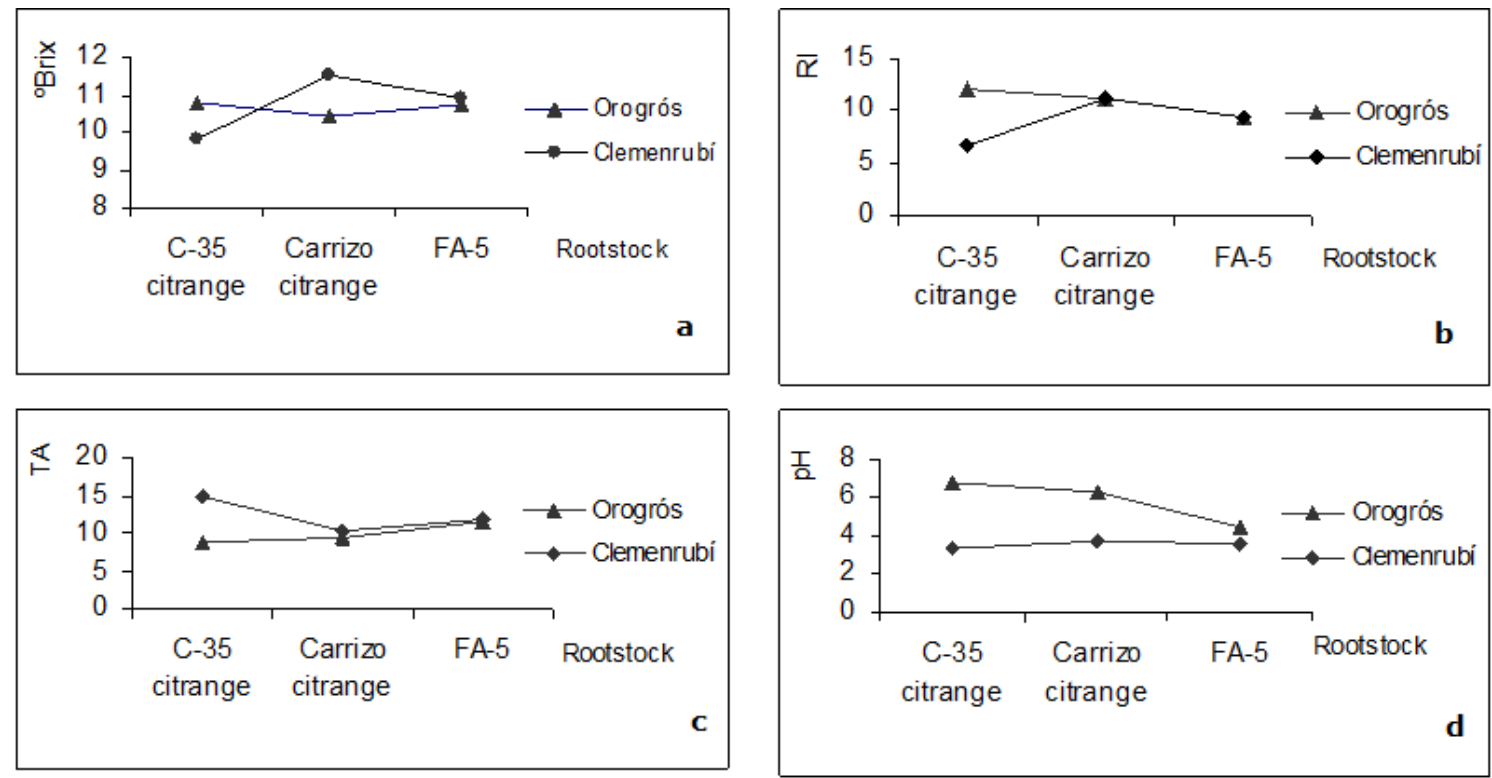

Figure 1. 

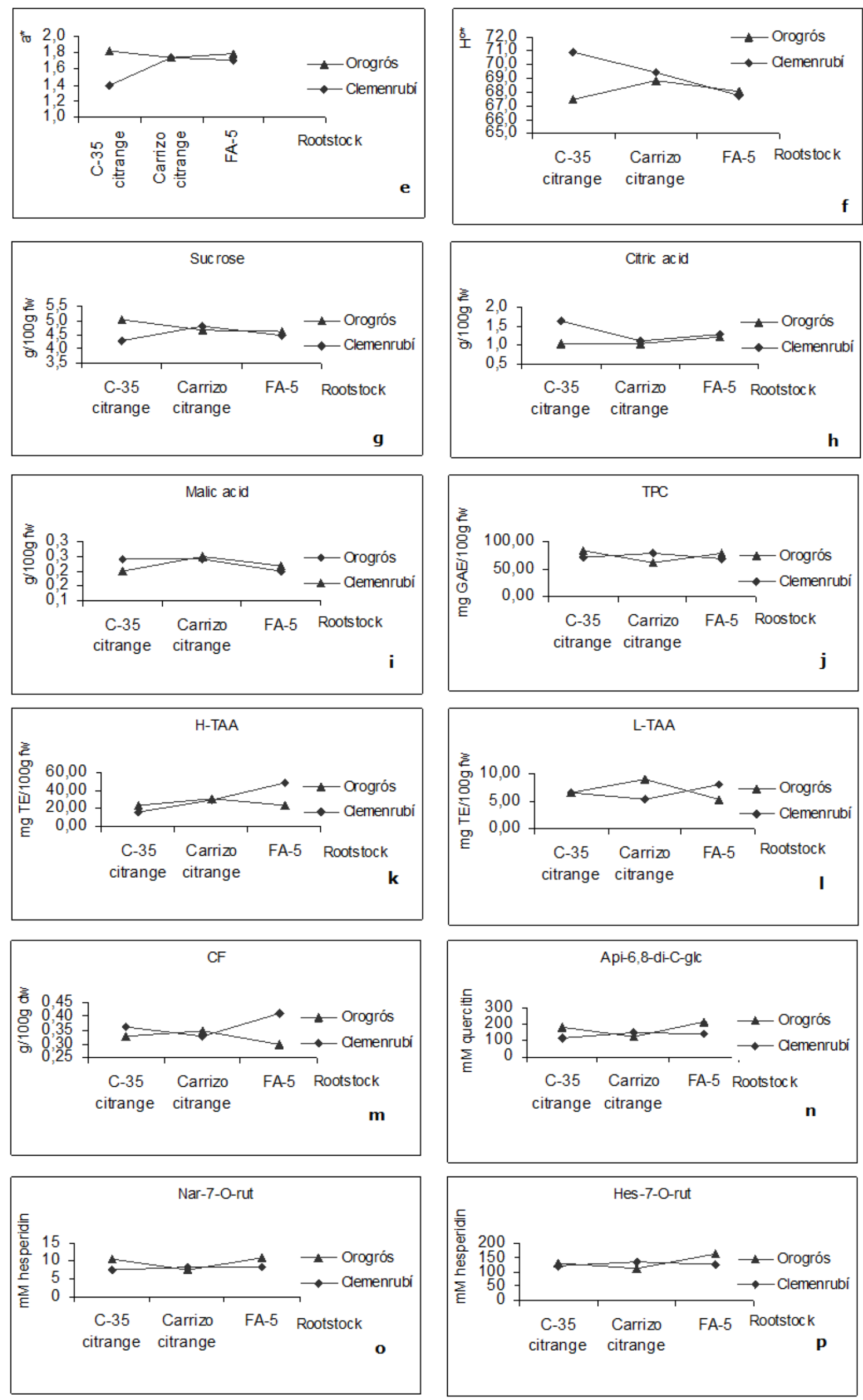

Figure 1. Interaction graphics rootstock $x$ variety for TSS (a), RI (b), TA (c), pH (d), $a^{*}(e), H^{\circ *}(f)$, sucrose (g), citric acid (h), malic acid (i), TPC (j), H-TAA (k), L-TAA (1), CF (m), Api-6,8-di-C-glc (n), Nar-7-O-rut (o) and Hesp-7-O-rut (p) 


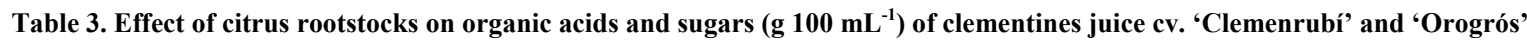

\begin{tabular}{|c|c|c|c|c|c|c|}
\hline aParameters & Glucose & Fructose & Sucrose & Citric & Malic & Ascorbic \\
\hline \multicolumn{7}{|l|}{ Rootstock } \\
\hline Carrizo citrange & 1.7 & 2.4 & 4.7 & $1.1 \mathrm{~b}^{\mathrm{b}}$ & $0.24 \mathrm{a}$ & 0.045 \\
\hline C-35 citrange & 1.8 & 2.5 & 4.6 & $1.3 \mathrm{a}$ & $0.22 \mathrm{~b}$ & 0.042 \\
\hline FA-5 & 1.8 & 2.5 & 4.5 & $1.2 \mathrm{a}$ & $0.21 \mathrm{~b}$ & 0.041 \\
\hline \multicolumn{7}{|l|}{ Variety } \\
\hline Clemenrubí & 1.9 & 2.7 & 4.5 & 1.3 & 0.22 & 0.04 \\
\hline Orogrós & 1.6 & 2.3 & 4.7 & 1.1 & 0.22 & 0.03 \\
\hline \multicolumn{7}{|l|}{ ANOVA $^{\mathrm{a}}$} \\
\hline Rootstock & NS & NS & NS & $* * *$ & $* *$ & NS \\
\hline Variety & $* * *$ & $* * *$ & $*$ & $* * *$ & NS & $*$ \\
\hline Rootstock x Variety & NS & NS & $* *$ & $* * *$ & ** & NS \\
\hline
\end{tabular}

${ }^{a} \mathrm{NS}=$ not significant at $\mathrm{p}<0.05 ; *, * *$, and ${ }^{* * *}$, significant at $\mathrm{p}<0.05,0.01$, and 0.001 , respectively.

${ }^{\mathrm{b}}$ Values followed by the same letter, within the same column, were not significantly different $(\mathrm{p}<0.05)$, according to Least significant difference test (LSD).

Table 4. Effect of citrus rootstocks on total phenolic content (TPC), total antioxidant activity (TAA) and crude fibre (CF) of clementines cv. 'Clemenrubí' and 'Orogrós'

\begin{tabular}{lllll}
\hline${ }^{a}$ Parameters & TPC & H-TAA & L-TAA & CF \\
\hline Rootstock & & & & \\
Carrizo citrange & 69.5 & $30.5 \mathrm{~b}^{\mathrm{b}}$ & $19.7 \mathrm{c}$ & 0.34 \\
C-35 citrange & 75.7 & $35.5 \mathrm{a}$ & 6.5 & 0.34 \\
FA-5 & 73.0 & & 6.7 & 0.35 \\
Variety & & & \\
Clemenrubí & 72.2 & 31.0 & 6.7 & 0.36 \\
Orogrós & 73.3 & 26.2 & 7.0 & 0.32 \\
ANOVA & & & \\
Rootstock & & & $\mathrm{NS}$ & $\mathrm{NS}$ \\
Variety & $\mathrm{NS}$ & $* * *$ & $\mathrm{NS}$ & $* *$ \\
Rootstock x Variety & $\mathrm{NS}$ & $* *$ & $* *$ & $* *$ \\
\hline
\end{tabular}

${ }^{\mathrm{a}} \mathrm{NS}=$ not significant at $\mathrm{p}<0.05 ; *^{* * *}$, and ${ }^{* * *}$, significant at $\mathrm{p}<0.05,0.01$, and 0.001 , respectively.

${ }^{\mathrm{b}}$ Values followed by the same letter, within the same column, were not significantly different $(\mathrm{p}<0.05)$, according to Least significant difference test (LSD).

TPC, mg GAE $100 \mathrm{~g}^{-1} \mathrm{fw}$; TAA, mg TE $100 \mathrm{~g}^{-1} \mathrm{fw}$; $\mathrm{CF}, \mathrm{g} 100 \mathrm{~g}^{-1} \mathrm{dw}$.

\subsection{Sugars and Organic Acids}

The factor "variety" significantly affected sugars and organic acids content, while the factor "rootstock $\times$ variety" only affected sucrose, citric and malic acids (Table 3 ). Clemenrubí fruits on C-35 citrange, FA-5 and Carrizo citrange had significantly more glucose and fructose that 'Orogrós' fruits. However, a significant interaction "rootstock $\times$ variety" was found for sucrose of the fruit juice, so the 'Orogrós' fruits had more sucrose that 'Clemenrubí' fruits grafted on C-35 citrange and FA-5 (Figure 1g). The lowest citric acid values were obtained on Carrizo citrange, while the highest citric acid values were obtained on C-35 citrange and FA-5 (Table 3). The 'Clemenrubí' fruits grafted on C-35 citrange showed the higher citric acid (Figure 1h). The highest malic acid values were recorder in 'Clemenrubí' and 'Orogrós' trees grafted on Carrizo citrange (Figure 1i). Our results show how interaction "rootstock $\times$ variety" influence sugars and organic acids of Clementine.

\subsection{Total Antioxidant Activity, Total Phenolic Content and Crude Fiber}

The effects of rootstock/scion combinations on antioxidant activity, total phenolic and crude fibre of clementines have not been studied in a systematic and comprehensive manner previously. The results obtained indicate that the interaction "rootstock $\times$ variety" significantly affected to antioxidant activity, total phenolic and crude fiber (Table 4 and Figure $1 \mathrm{j}, \mathrm{k}, 1, \mathrm{~m}$ ). The highest TPC values were recorded in 'Orogrós' trees grafted on C-35 citrange and FA-5, however the 'Clemenrubí' trees recorded the higher values of TPC grafted on Carrizo citrange (Figure $1 \mathrm{j}$ ). Results from TAA (both H-TAA and L-TAA) showed that the rootstock FA-5 induced the higher H-TAA for 'Clemenrubí' fruits while that it induced the lower H-TAA for 'Orogrós' fruits (Figure $1 \mathrm{k}$ ); however the rootstock Carrizo citrange induced the higher L-TAA for 'Clemenrubí' fruits and the lower for 'Orogrós' fruits (Figure 1 1). The crude fiber content also was affected by 
interaction "rootstock $\times$ variety" (Table 4 , Figure $1 \mathrm{~m})$. In this case, also the rootstock FA-5 induced the higher crude fiber content for 'Clemenrubí' fruits while that it induced the lower values of crude fiber for 'Orogrós' fruits (Figure $1 \mathrm{~m}$ ). These results show the high degree of interaction between rootstock/scion.

\subsection{Identification and Quantification of Phenolic Compounds}

Flavonoids are widely distributed in fruits and each species is characterized by a particular flavanone glycoside pattern [12]. Several authors have evaluated the effect of the rootstock in relation to flavonoid content in Citrus $s p$. and observed that it could be an important agronomic factor in total flavonoid content [25]. In this study six flavonoids are detected in clementines cv. 'Clemenrubí' and 'Orogrós' (Figure 2). The interaction "rootstock $\times$ variety" significantly affected to flavanones and C-glucosides. As shown in Table 5, the Orogrós cv, grafted onto FA-5 rootstock presented the highest amounts of Api-6,8-di-C-glc, Nar-7-O-rut, and Hes-7-O-r flavonoids (Figure 1n, o, and p). In this study, we found significantly differences between rootstock in relation to flavonoid content. So, the rootstock FA-5 produced the major flavonoid content; while Carrizo citrange and C-35 citrange rootstocks showed similar tendencies with not significant differences. Depending on the fruit development stage, the presence and /or concentrations of flavonoids can be affected. So, most Citrus species accumulate substantial quantities of flavonoids during their organ development [26].

Table 5. Effect of citrus rootstocks on polyphenols profile (Flavanones and C-glucosides) of clementines cv. 'Clemenrubí' and 'Orogrós'

\begin{tabular}{|c|c|c|c|c|c|c|}
\hline${ }^{\mathrm{a}}$ Parameters & Api-6,8-di-C-glc & Dios-6-C-glc & Api-7-O-rut & Nar-7-O-rut & Hes-7-O-rut & Didymin \\
\hline \multicolumn{7}{|l|}{ Rootstock } \\
\hline Carrizo citrange & $137.8 b^{b}$ & $101.9 \mathrm{~b}$ & $507.6 \mathrm{~b}$ & $7.8 \mathrm{~b}$ & $122.8 \mathrm{~b}$ & 280.9 \\
\hline C-35 citrange & $151.8 \mathrm{~b}$ & $104.5 \mathrm{~b}$ & $504.0 \mathrm{~b}$ & $9.6 \mathrm{ab}$ & $127.1 \mathrm{~b}$ & 268.9 \\
\hline FA-5 & $180.5 \mathrm{a}$ & $120.9 \mathrm{a}$ & $557.3 \mathrm{a}$ & $8.7 \mathrm{a}$ & $143.3 \mathrm{a}$ & 295.2 \\
\hline \multicolumn{7}{|l|}{ Variety } \\
\hline Clemenrubí & 137.3 & 103.5 & 510.5 & 8.0 & 127.4 & 281.1 \\
\hline Orogrós & 176.2 & 114.7 & 535.4 & 9.4 & 134.7 & 282.3 \\
\hline \multicolumn{7}{|l|}{ ANOVA $^{\mathrm{a}}$} \\
\hline Rootstock & $* *$ & $*$ & $*$ & $*$ & $* *$ & NS \\
\hline Variety & $* *$ & $*$ & NS & $*$ & NS & NS \\
\hline Rootstock x Variety & $* * *$ & NS & NS & $*$ & $* *$ & NS \\
\hline
\end{tabular}

${ }^{\mathrm{a}} \mathrm{NS}=$ not significant at $\mathrm{p}<0.05 ; *, *$, and $* * *$, significant at $\mathrm{p}<0.05,0.01$, and 0.001 , respectively.

${ }^{\mathrm{b}}$ Values followed by the same letter, within the same column, were not significantly different $(\mathrm{p}<0.05)$, according to Least significant difference test (LSD)

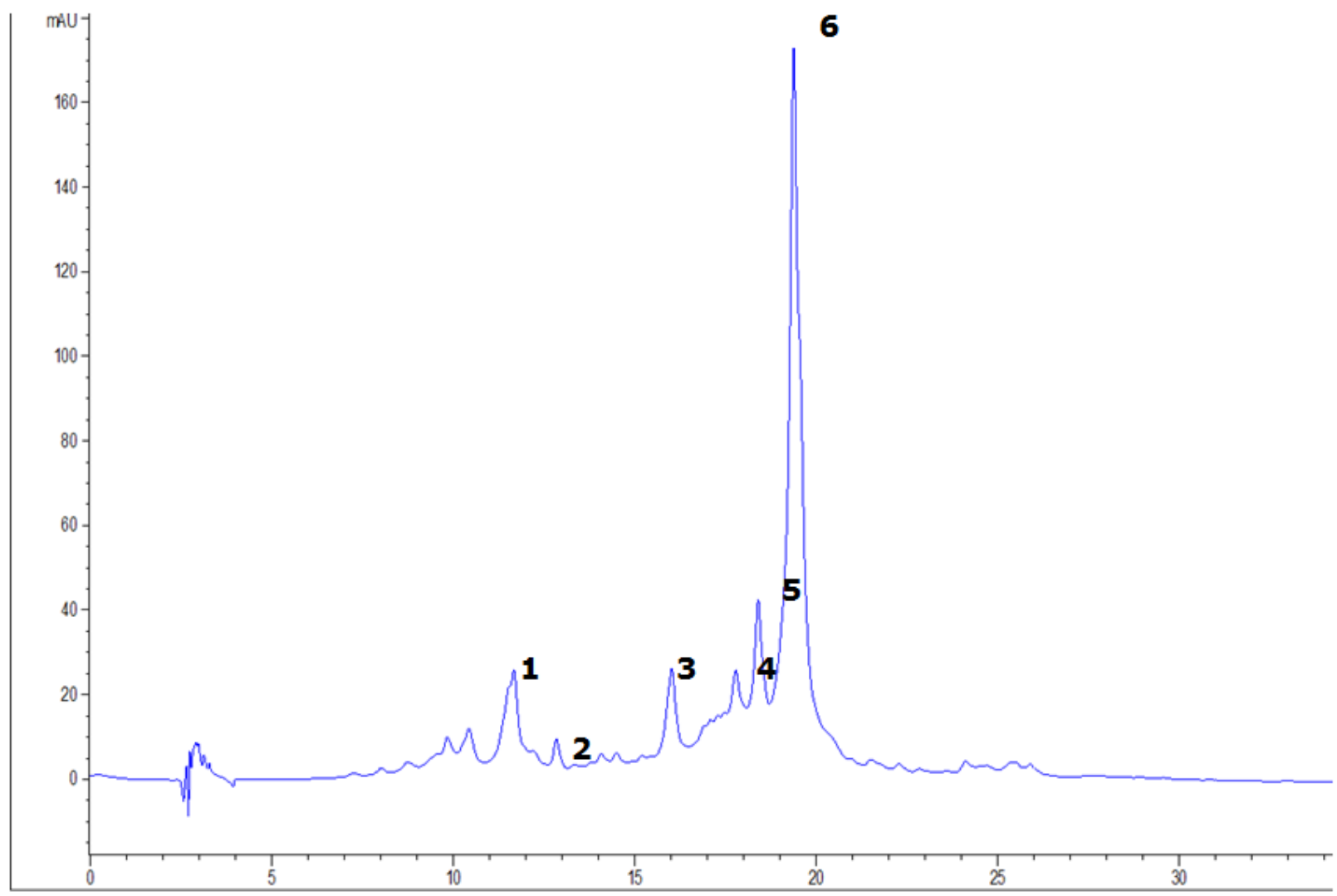

Figure 2. Chromatogram of polyphenolic profile (Flavanones and C-glucosides) of clementines (1 Api-6,8-di-C-glc (11.6 min); 2 Dios-6-C-glc (12.9 min); 3 Didymin (16.0 min); 4 Nar-7-O-rut (17.8 min); 5 Api-7-O-rut (18.2 min); 6 Hes-7-O-rut (19.5 min)) 


\section{Conclusions}

To our knowledge this is the first study that examined the influence of citrus rootstocks (Carrizo citrange, C-35 citrange and F-5) in bioactive compounds of clementines cv. 'Clemenrubí' and 'Orogrós'. The present results indicate that the effect of rootstock on the physicochemical parameters, antioxidant activity, total phenolic, sugars and organic acids and flavonoids of clementines fruits is a rather complex phenomenon that greatly depends on specific interactions between the rootstock and each particular scion variety. So, C-35 citrange rootstock produced the heaviest and bigger size fruits, while the rootstock FA-5 produced the fruit with the major flavonoid content.

\section{Acknowledgements}

This work was funded by the Instituto Nacional de Investigación y Tecnología Agraria y Alimentaria (RTA2014-0059), Generalitat Valenciana, and FEDER funds.

\section{References}

[1] FAO (Food and Agriculture Organization of the United Nations). FAOSTAT [on line]. 2014. Available:

http://faostat3.fao.org/download/Q/QC/E [Accessed May 17, 2017].

[2] Castle WS. Career perspective on citrus rootstocks, their development and commercialization. HortScience 45: 11-15, 2010a.

[3] Castle WS, Baldwin JC, Muraro RP, Littel R. Performance of "Valencia" sweet orange trees on 12 rootstocks at two locations and an economic interpretation as a basis for rootstock selection. HortScience 45: 523-533, $2010 \mathrm{~b}$.

[4] Cantuarias-Aviles, T, Maurao FAA, Stuchi ES, da Silva SR, Espinoza-Nuñez E. Tree performance and fruit yield and quality of "Okitsu" Satsuma mandarin grafted on 12 rootstocks. Sci Hortic 113: 318-322, 2010.

[5] Benjamin G, Tietel Z, Porat R. Effects of rootstock/scion combinations on the flavor of citrus fruit. J Agric Food Chem. 61: 11286-11294, 2013.

[6] MAPA (2013a). Estadísticas Agrarias [on line] Available: http://www.magrama.gob.es/es/estadistica/temas/estadisticasagrari as/agricultura/default.aspx [Accessed May 2, 2017].

[7] Cameron JW, Soost RK. C35 and C32: citrange rootstocks for citrus. HortScience 21: 157-158, 1986.

[8] Forner-Giner MA, Primo-Millo E, Forner JB. Performance of Forner-Alcaide 5 and Forner-Alcaide 13, Hybrids of Cleopatra Mandarin $\times$ Poncirus Trifoliata, As Salinity-Tolerant Citrus Rootstocks. J Am Pomol Soc 63: 72-80, 2009.
[9] Llosá MJ, Bermejo A, Cano A, Forner-Giner MA. The citrus rootstocks Cleopatra mandarin, Poncirus Trifoliata, FornerAlcaide 5 And Forner-Alcaide 13 vary in susceptibility to iron deficiency chlorosis. J Am Pomol Soc 63 (4): 160-167, 2009.

[10] Verdejo-Lucas S, Galeano M, Sorribas FJ, Forner JB, Alcaide A. Effect on resistance to Tylenchulus semipenetrans of hybrid citrus rootstocks subjected to continuous exposure to high population densities of the nematode. Eur J Plant Pathol 109: 427-433, 2003.

[11] Forner-Giner M A, Alcaide A, Primo-Millo E, Forner J B. Performance of Navelina orange on 14 rootstocks in Northern Valencia (Spain). Sci Hortic 98: 223-232, 2003.

[12] Cano A, Bermejo A. Influence of rootstock and cultivar on bioactive compouds in citrus peel. J Sci Food Agric 91: 1702-1711, 2011.

[13] MAPA. Métodos Oficiales de Análisis. Tomo I: 344-346, 1993 b.

[14] Legua P, Forner JB, Hernández F, Forner-Giner MA. Physicochemical properties of orange juice from ten rootstocks using multivariate analysis. Sci Hortic 160: 268-273, 2013.

[15] Legua P. Hernández F. Díaz-Mula HM, Valero D, Serrano M. Quality, bioactive compounds and antioxidant activity of new flattype peach and nectarine cultivars: a comparative study. J Food Sci 76: C729-C735, 2011a.

[16] Singleton VL, Orthofer R, Lamuela-Raventós RM. Analysis of total phenols and other oxidation substrates and antioxidants by means of Folin-Ciocalteu reagent. Method Enzymol 299: 152-178, 1999.

[17] Legua P, Bellver R, Forner J, Forner-Giner MA. Plant growth, yield and fruit quality of "Lane Late" navel orange on four citrus rootstocks. Span J Agric Res 9: 271-279, 2011 b.

[18] Tuzcu Ö, Yildrim B, Yesiloglu T. Effect of different rootstocks and sector son fruit yield and its distribution to the tree canopy. Procceding International Society Citriculture, X Congress, Agadir, Morocco, 405-408, February 2004.

[19] García-Sánchez F, Pérez-Pérez JG, Botía P, Martínez V. The response of young mandarin trees grown under saline conditions depends on the rootstock. Eur J Agron 24: 129-139, 2006.

[20] Demirkeser TH, Kaplankiran M, Yildiz E. The effects of some citrus rootstocks on fruit yield and quality for Rohde Red Valencia orange during the period of the juvenility in Doryol (Hatay-Turkey) conditions. $7^{\text {th }}$ International Society of Citrus Nurserymen Congress. Cairo, Egypt, No 28, september 17-21 2005.

[21] Tounsi MS, Wannes W, Ouerghemmi I, Jegham S, Njima YB, Hamdaoui G, Zemnin H, Marzouk B. Juice components and antioxidant capacity of four Tunisian citrus varieties. J Sci Food Agric 91: 142-151, 2011.

[22] Harding PL, Fisher DF. Seasonal changes in Florida grapefruits. United Stated Department of Agriculture, Technical Bulletin: 886, 1945.

[23] Navarro JM, Pérez-Pérez J, Romero P, Botía P. Analysis of the changes in quality in mandarin fruit, produced by deficit irrigation treatments. Food Chem 199: 1591-1596, 2010.

[24] Olmo M, Nadas A, García JM. Nondestructive methods to evaluate maturity level of oranges. J Food Sci 65: 365-369, 2000.

[25] Gil-Izquierdo A, Riquelme MT, Porras I, Ferreres F. Effect of the rootstock and interstock grafted in lemon tree (Citrus limon (L.) Burm.) on the flavonoid content of lemon juice. J Agric Food Chem 52: 324-331, 2004.

[26] Mata M L, Andrés-Lacueva C, Jáuregui O, Lamuela-Raventós RM. Determination of flavonoids in a Citrus fruit extract by LC-DAD and LC-MS. Food Chem 101: 1742-1747, 2007. 